İlkbal Temel Yüksel ๑ Sema Karakaş 10 Sedat Akgöl ๑ (ASC-US) Kadınların Kolposkopisinde Displastik Lezyonların Saptanmasında Endoservikal Kürtajın Kullanımı

Niyazi Alper Seyhan (D Gizem Kul (1) İpek Yıldız Özaydın (1) Özgür Akbayır (1)

\title{
Use of Endocervical Curettage for Detecting Dysplastic Lesions at Colposcopy of Women With Atypical Squamous Cells of Undetermined Significance (ASC-US)
}

öz

Amaç: Pap smeari ASC-US (Önemi Belirlenemeyen Atipik Skuamöz Hücreli) olan kadınların endoservikal küretaj (ECC) örneklerinde displastik lezyon sıklığını belirlemek ve bu ECC örneklerinde yüksek gradeli displazi ile ilişkili muhtemel faktörleri değerlendirmektir.

Yöntem: Ocak 2017 - Haziran 2019 tarihleri arasinda Pap smear sonucu ASC-US olan ve kolposkopik muayene sırasında ECC yapılan hastalar retrospektif olarak incelendi. Hastaların demografik verileri ve patoloji sonuçları değerlendirildi.Histopatolojik veriler, CIN (servikal intraepitelyal neoplazi) 2'den daha az (servisit, atrofi, servikal polip, metaplazi ve CIN 1) ve CIN 2+ (CIN 2/3/CIS karinoma insutu) ve invaziv/mikroinvaziv kanser) lezyonlar olmak üzere 2 kategoride sınıflandırıldı. CIN 2+ risk faktörlerini değerlendirmek için risk oranları hesaplandı.

Bulgular: Toplam 901 hasta çalısmaya dahil edildi. Yetersiz kolposkopik muayenesi olan hastaların \%7.4'sinde CIN 2+ lezyon tespit edildi. Koloskopik muayenesi yeterli olan ve olmayan hastalar arasında endoservikal kanal displazisi açısından istatistiksel olarak anlamlı fark saptandı $(p=0.005)$. Bunun yanında servikal biyopsi sonucu CIN $2+$ olan hastaların endoserviksinde CIN $2+$ lezyon olma olasılığı diğer grupla kıyaslandığında istatistiksel olarak fark bulundu $(p=0.001)$. Yetersiz kolposkopi ve servikal biyopsisi CIN 2+ olan hastalarda endoservikal kanalda CIN 2+ görülme riski sırasıyla 24 ve 139 kat yüksekti.

Sonuç: Pap smearde ASC-US sitolojisi olan kadınların endoservikal kanallarında yüksek dereceli CIN sıklığı düşüktür. Endoservikal kanalda yüksek dereceli displazinin öngörücüsü olarak yüksek dereceli ektoservikaldisplazi ve yetersiz kolposkopi kullanılabilir ve bu hastalarda ECC yapılması uygun olabilir.

Anahtar kelimeler: endoservikal küretaj, kolposkopi, ASC-US

\section{ABSTRACT}

Objective: To determine the frequency of dysplastic lesions in Endocervicalcurettage(ECC) specimens of women with ASC-US (Atypical Squamous Cells of Undetermined Significance) and to evaluate possible factors associated with high-grade dysplasia in these ECC specimens. Method: The patients who had ASC-US result in Pap smear between January 2017 and June 2019 and who underwent ECC during colposcopic examination were retrospectively analyzed. Demographic data and pathology results of the patients were evaluated. Histopathological data were categorized into two categories as less than CIN 2 (cervicitis, atrophy, cervical polyp, metaplasia and CIN 1) and CIN2 + (CIN 2/3 / CIS (carcinoma in sutu) and invasive / microinvasive cancer) lesions. Risk ratios were calculated to evaluate CIN $2+$ risk factors.

Results: A total of 901 patients were included in the study. CIN 2+ lesions were detected in $7.4 \%$ of patients with inadequate colposcopic examination. There was a statistically significant difference in endocervical canal dysplasia between the patients with and without sufficient coloscopic examination $(p=0.005)$. There was a statistically significant difference in the presence of CIN $2+$ lesion in the endocervix of patients with CIN2 + cervical biopsy $(p=0.001)$. In patients with inadequate colposcopy and positive cervical biopsy, the risk of CIN $2+$ in the endocervical canal was 24 and 139 times higher, respectively.

Conclusion: Women with ASC-US cytology in Pap smear have a low incidence of high-grade CIN in the endocervical canal. High-grade ectocervical dysplasia and insufficient colposcopy can be used as predictors of high-grade dysplasia in the endocervical canal and ECC may be acceptable in these patients

Keywords: endocervical curettage, colposcopy, ASC-US
Alındığı tarih: 07.12.2019

Kabul tarihi: 20.05 .2020

Yayın tarihi: 31.05 .2020

Atıf vermek için: Yüksel iT, Karakas S, Akgöl S, Seyan NA, Kul G, Özaydm IY, Akbayr Ö. Ön Sey NA, Kul G. Ozaydr IY, Akbayr O. (ASC-US) kadınların kolposkopisinde displastik lezyonların saptanmasında endoservikal kürtajın kullanımı. IKSSTD 2020;12(2): 151-5.

ilkbal Temel Yüksel S.B.Ü. Kanuni Sultan Suleyman Eğitim ve Araştırma Hastanesi Jinekolojik Onkoloji Kliniği İstanbul - Türkiye drilkbaltemel@gmail.com ORCiD: 0000-0002-7337-9977

S. Akgöl 0000-0001-8609-3049

Ö. Akbayır 0000-0002-2699-4969 S.B.Ü. Kanuni Sultan Suleyman EAH Jinekolojik Onkoloji Kliniği Istanbul - Türkiye

S. Karakaş 0000-0002-2795-4766 S.B.Ü. Sadi Konuk EAH Jinekolojik Onkoloji Kliniği Istanbul - Türkiye

N. A. Seyhan 0000-0003-0543-6180 Tekirdağ Devlet Hastanesi Jinekolojik Onkoloji Kliniği Tekirdağ - Türkiye

G. Kul 0000-0001-6392-0355 Sebinkarahisar Devlet Hastanesi Kadın Hastalıkları ve Doğum Kliniği Giresun - Türkiye

i. Y. Özaydın 0000-0003-3653-9641 S.B.Ü. Kanuni Sultan Suleyman EAH Patoloji Kliniği istanbul - Türkiye 


\section{Giriş}

Endoservikal küretaj (ECC), endoservikal kanalın bir küret ile çevresel olarak kazınmasını içeren prosedürdür. Genelde ECC'nin belirli popülasyonlarda (gebeler) yapılmaması gerektiği konusunda fikir birliği olmasına rağmen, ECC'nin hangi hastaya yapılması gerektiği konusunda tartışmalar devam etmektedir (1). Bazı kolposkopistler, ECC yapılmasının endoservikal kanalda prekanseröz ve invazivservikal kanserin kaçırılmasını önleyebileceğini düşünürler ve gebe olmayan tüm kadınların kolposkopik muayenelerinde, kolposkopik bulguları normal olmasına ve tüm transformasyon bölgesinin görülmesine rağmen, ECC yapmayı tercih ederler (2-6). Öte yandan, diğer kolposkopistler ECC'nin gereksiz bir prosedür olduğunu ve sadece seçilmiş vakalarda yapılması gerektiğini öne sürerler ${ }^{(7-9)}$.

Amerikan Kolposkopi ve Servikal Patoloji Derneği, yüksek gradeli sitolojisi, kolposkopik muayenede kesin lezyonu olmayan düşük gradeli sitolojisi veya kolposkopik incelemenin yetersiz olduğu kadınlarda ECC'yi önerir. Bununla birlikte, yeterli bir kolposkopi ve kolposkopide görünür lezyonu olan düşük gradeli sitolojisi olan kadınlarda, ECC zorunlu olmamakla beraber kabul edilebilir bir prosedürdür (10). Dolayısıyla, Pap smeari ASC-US olan kadınlarda ECC'nin yapılması netlik kazanmamıştır.

Biz çalışmamızda Pap smeari ASC-US olan kadınların ECC örneklerinde displastik lezyon sıklığını belirlemeyi ve bu ECC örneklerinde yüksek gradeli displazi ile ilişkili muhtemel faktörleri değerlendirmeyi amaçladık.

\section{GEREÇ ve YÖNTEM}

Ocak 2017-Haziran 2019 tarihleri arasında Pap smear sonucu ASC-US olması nedeniyle kolposkopi yapılan hastalar retrospektif olarak incelendi. Kolposkopik muayene sırasında ECC yapılan tüm hastalar çalışmaya dahil edildi. Patoloji sonucu olmayan ve smear sonucunda endoservikal hücre varlığı olan hastalar çalışma dışı bırakıldı. Yaş, parite, menopoz durumu ve kolposkopik biyopsi ve ECC patoloji sonuçlarını içeren demografik veriler toplandı.

Kolposkopik muayeneler jinekolojik onkologlar tarafından servikse \%3-5 asetik asit solüsyonu uygulandıktan sonra yapıldı. Tüm skuamokolumnar bileşke görüldüğünde muayene yeterli kabul edildi. Asetik asit uygulamasından sonra, düz veya hafif yükselmiş, çoğunlukla iyi sınırlı, asetowhite lezyon, punktuat patern veya mozaik patern saptandığında kolposkopik sonuç pozitif olarak kabul edildi. Servikal biyopsi örnekleri servikal intraepitelyal neoplazi (CIN) için şüpheli alandan alındı. Eğer muayene sırasında skuamokolumnar bileşke görünmüyorsa kolposkopi "yetersiz" olarak tanımlandı. ECC, transformasyon bölgesinin veya proksimal servikal lezyonun geniş ölçüde yeterince görselleştirilmediği durumlarda yapıldı. ECC, rutin lokal uygulama sonrası novak küret ile yapıldı ve histopatolojik örnek alındı. Klinik tedavi, patologlarının histolojik tanısına göre yapıldı. Bu çalışmada yeterli endoservikal örneklemesi olan hastalar analiz edildi. Histopatolojik veriler, CIN 2'den daha az (servisit, atrofi, servikal polip, metaplazi ve CIN 1) ve $\mathrm{CIN} 2+$ (CIN 2/3/CIS (karsinoma insitu) ve invaziv/mikroinvaziv kanser) lezyonlar olmak üzere 2 kategoride sınıflandırıldı. Univariate analizde anlamlı çıkanlar multivariate analizi ile değerlendirildi.

Verilerin İstatistiksel Analizi

Veriler 'SPSS version 20.0 statistical program' kullanılarak analiz edildi. Devamlı değişkenlerin dağılımı Kolmogorov-Smirnov testi ile analiz edildi. Devamlı değişkenlerin karşılaştırılmasında dağılımın normal veya anormal olmasına göre Student-t test ve MannWhitney U testi kullanıldı. Univariate analizlerde CIN 2+ risk faktörlerini değerlendirmek için Pearson Ki-Kare testi ve Fisher Exact test kullanıldı. Lojistik regresyon analizinde enter metodu ile değişkenler seçildi ve ilk kategoriler referans olarak alınarak risk oranları (Risk ratio) hesaplandı. Sonuçlar \% 95 güven aralığında, $p<0,05$ anlamlılık düzeyinde değerlendirildi.

\section{BULGULAR}

Çalışmaya toplam 901 hasta dahil edildi. Hastaların ortalama yaşı $43 \pm 11$ idi. 901 kadından 708 (\%78.6)'i premenopozal dönemde, 193 (\% 21.4)'ü menopozal dönemdeydi.

Kolposkopik muayene 807 hastada (\%89.6) kolposkopik inceleme yeterliydi. 149 (\% 16.5) unda biyopsi yapılmadı. Hastaların 42 (\% 4.7)'sinde endoservikal kanalda CIN 1 lezyon saptandı ve CIN 2/3/CIS ve invaziv/mikroinvaziv kanser oranlarısırasıyla \%2.8 $(n=25)$ ve\% $0.1(n=1)$ idi. 
I. T. Yüksel ve ark., Önemli Belirlenemeyen Atipik Skuamöz Hücreli (ASC-US) Kadınların Kolposkopisinde Displastik Lezyonların Saptanmasında Endoservikal Kürtajın Kullanımı

Tablo 1 ve Tablo 2'de endoservikal kanalda CIN 2+ lezyonu olan ve olmayan hastaların klinikopatolojik özelliklerini göstermektedir. CIN 2+ lezyon, yetersiz kolposkopik muayenesi olan hastaların \%7.4 (7/94) sinde tespit edildi. Koloskopik muayenesi yeterli olan ve olmayan hastalar arasında endoservikal kanal displazisi açısından istatistiksel olarak anlamlı fark saptandı $(p=0.005)$. Endoservikal kanalında CIN 2+ lezyon olan 17 (\% 65.4) hastanın servikal biyopsi sonucunda CIN 2+ lezyon vardı ( $p=0.013)$. CIN 2'den daha az biyopsi sonucu olan hastaların 4 (4/695)'ünde endoservikal kanalda CIN 2 veya daha yüksek dereceli lezyonlar vardı.

Univariate analizde anlamlı çıkanlar multivariate analizi ile değerlendirildi. Multivariate lojistik regresyon analizinde yeterli kolposkopi ve servikal biyopsi pozitif olan hastalarda endoservikal kanalda CIN $2+$ görülme riski sırasıyla 3.3 ve 73.4 kat yüksekti. Tablo 3 'de multivariate lojistik regresyon analizini göstermektedir.

\section{TARTIŞMA}

Sitolojik anomalileri olan hastalarda endoservikal kanalın değerlendirilmesi, kolposkopik inceleme ile görülemeyebilecek bir lezyonun varlığının belirlenmesi için önemlidir. Bununla birlikte, ECC için kesin endikasyonlar tartışılmaya devam etmektedir (1). Gebelikte belirgin kontrendikasyonun yanı sıra, yaşlı kadınlarda skuokolumnar bileşkenin tamamen görselleştirilmesindeki zorluktan dolayı ECC uygulamanın yararları konusunda fikirbirliği vardır. Ancak, ECC'yi yapmanın gerekli olduğu yaş için cut off değeri kılavuzlarda belirtilmemiştir ${ }^{(10)}$. Sitolojiye ve kolposkopik anormalliklere göre ECC'den en fazla yararlanacak kadınları belirleyen çalışmaların sonuçları, ECC uygulanan kadınların seçiminde biaslar olması nedeniyle yeterli değildir ${ }^{(11-15)}$.

Massad ve ark. ${ }^{(7)}$, tüm anormal sitolojik smeare sahip hastalarda anormal ECC sonucunun belirleyicilerini değerlendirmişler ve yaş, parite, ilk cinsel ilişki yaşının ve yetersiz kolposkopinin, anormal ECC sonuçları ile ilişkili faktörler olduğunu göstermişlerdir. Poomtavorn ve ark. ${ }^{(16)}$ ise, endoservikal kanalda, yaş, parite, ilk cinsel ilişkideki yaş ile yetersizkolposkopi ve yüksek dereceli displazi lezyonları arasında ilişki bulmamıştır. Biz çalışmamızda; yetersiz kolposkopi ve kolposkopik muayenede yüksek gradeli lezyon şüphesi olan hastaların endoservikal kanalda yüksek gradeli lezyonlarla ilişkili olduğunu bulduk, fakat yaş, menopoz ve parite ile ilişkili bulmadık. Bu nedenle, kolposkopik muayenelerde şüpheli yüksek gradeli lezyonuve yetersiz kolposkopik değerlendirmesi olan hastalarda endoservikal kanalı değerlendirmek için ECC yapılabilir. Pap smeari ASC-US olan hastaların 25'inde (\%2.8), endoservikal kanalda CIN 2-3 lezyonları vardı. Çalışmamızdaki Papsmeari ASCUS olan hastaların yüksek gradeli endoservikal displazi sıklığı önceki çalışmalarda bildirilenlerle benzerdir (\% 0.8-4.0) ${ }^{(8,12)}$. Çalışmaya katılan hastaların \%10.5'inde kolposkopik incelemenin yetersiz olduğu tespit edildi. Bu oranın daha önceki çalışmalarda \% 5- 45.9 arasında değiştiği bildirilmiştir ${ }^{(17-20)}$.

Massad ve ark. ${ }^{(21)}$, yetersiz kolposkopisi olan tüm anormal servikal smear sitolojili hastaların endoservikal kanaldaki displastik lezyon prevalansının yeterli kolposkopik muayeneye göre daha fazla olduğunu (\%31'e karşı \%17) bildirmişlerdir. Bizde çalışmamızda yetersiz ve yeterli kolposkopik muayenesi olan hastalar arasında yüksek gradeli endoservikal displazi oranında istatistiksel olarak anlamlı fark bulduk (\% 7.4'e karşı \% 2.4). Massad ve arkadaşlarının çalışmasında, bizim çalışmamıza göre, yüksek gradeli endoservikal displazi oranının daha yüksek olmasının nedeni Massad ve arkadaşlarının çalışmasında Pap smeari HSIL olan hastaların da olmasından kaynaklanmaktadır.

Ferenczy, kolposkopi ile anormal sitoloji açısından değerlendirilen tüm kadınlara ECC yapılmasının, endoservikal kanalda hastalığı olmayan kadınlar için diagnostik soğuk konizasyonundan kaçınmaya yardımcı olacağını, bunun tersine pozitif ECC'li kadınların soğuk konizasyon veya daha kesin bir cerrahi işleme gönderilebileceğini desteklemiştir ${ }^{(2)}$. Williams ve arkadaşları, yeterli kolposkopik muayenesi olan ASC-US ve LSIL hastalarının endoservikal örneklerinde displastik lezyon oranının 159 hastanın 4'ünde (\% 2.5) olduğunu ve bu hastalarında tamamının sadece hafif endoservikal displaziye sahip olduğunu göstermişlerdir ${ }^{(22)}$. Bu nedenle, bu kadınlarda ECC'nin yapılamayabileceğini öne sürdüler. Çalişmamızda ECC sonuçlarının \%2.9'unda CIN 2+ teşhis edildi. ECC ile tanı alan ve biyopsi ile tanı almama oranımız \%0.6'ydı. Bu risk temelinde kolposkopi yapılan tüm hastalara ECC yapmalı mıyız sorusunun cevabı oldukça zordur. Başka bir açıdan bakıldığında ise hastalarımızın büyük bölümünde servikal ve ECC biyopsi sonuçları uyumluydu. Bu nedenle biyopsi sonucu 
servikal displazi açısından pozitif gelen hastalarda endoserviksin ECC ile değerlendirilmesinin uygun olabileceğini düşünüyoruz.

Çalışmamızda Endoservikal kanal displazisi açısından yüksek risk altındaki hastaları tanımlamak için yapılan multivariant analizde, yetersiz kolposkopik değerlendirmenin ASC-US sitolojisi olan hastalar için endoservikal kanal tutulumu için bağımsız risk faktörleri olduğunu gösterdik. Bulgularımız mevcut servikal kanser tarama kılavuzlarında ECC endikasyonları olan; (1) ASC-H veya HSILsitoloji; (2) yetersiz kolposkopi ile ASC-US veya LSIL sitolojisini, desteklemektedir.

Çalışmamızın güçlü yanı kolposkopik muayenelerin jinekolog onkologlar tarafından yapılmasıdır. Ancak çalışmamızın bazı kısıtıııkları vardı. Bunlar, çalışmamızın retrospektif olması ve yüksek gradeli endoservikal displazi ile ilişkili olabilecek bazı dermografik kayıtların tam olmamasıdır.

Sonuç olarak, ASC-US sitolojisi olan kadınların endoservikal kanallarında yüksek gradeli CIN sıklığı düşüktür. Bu nedenle, bu kadınlarda rutin ECC uygulaması tartışmalıdır. Endoservikal kanalda yüksek gradeli displazinin öngörüsünde yüksek gradeli ektoservikal displazi ve yetersiz kolposkopi kullanılabilir ve bu hastalarda ECC yapılması uygun olabilir.

Etik Kurul Onayı: İstanbul Dr Sadi Konuk Eğitim ve Araştırma Hastanesi Etik Kurulu'ndan onay alınmıştır (Numara:2019-515)

Çıkar Çatışması: Yazarlar herhangi bir çıkar çatışması bildirmemiştir.

Finansal Destek: Yazarlar bu çalışma için herhangi bir finansal destek almamıştır.

Hasta Onamı: Çalışma retrospektif dosya tarama şeklinde yapılmış olup, hastanemizde tedavi gören her hasta dosya açıldığında aydınlatılmış onam formu imzalamaktadır.

Ethics Committee Approval: Approval was obtained from the Ethics Committee of Istanbul Dr Sadi Konuk Training and Research Hospital (Number: 2019515).

Conflict of Interest: Authors did not declare any conflict of interest.

Funding: The authors received no specific funding for this work.

Informed Consent: The study was conducted as a retrospective file scan and each patient in our hospital signs an informed consent form when the file is opened.

\section{KAYNAKLAR}

1. Driggers RW, Zahn CM. To ECC or not to ECC: the question remains. Obstet Gynecol Clin North Am. 2008;35(4):583-97; viii. https://doi.org/10.1016/j.ogc.2008.09.007

2. Ferenczy A. Endocervical curettage has no place in the routine management of women with cervical intraepithelial neoplasia: debate. Clin Obstet Gynecol. 1995;38(3):644-8.

https://doi.org/10.1097/00003081-199509000-00024

3. Pretorius RG, Zhang $\mathrm{WH}$, Belinson JL, Huang $\mathrm{MN}$, Wu LY, Zhang $\mathrm{X}$, et al. Colposcopically directed biopsy, random cervical biopsy, and endocervical curettage in the diagnosis of cervical intraepithelial neoplasia II or worse. Am J Obstet Gynecol. 2004;191(2):430-4. https://doi.org/10.1016/j.ajog.2004.02.065

4. Puntachai $P$, Darojn D, Chumworathayi B, Chaousriku W. Comparing visual inspection with acetic acid plus random cervical biopsy plus endocervical curettage to colposcopic directed biopsy plus endocervical curettage in detecting cervical lesions in low-resource settings. Asian Pac J Cancer Prev. 2011;12(10):2665-8.

5. Schneider P, von Orelli S, Roos M, Leo C, Fink D, Wyss $P$. The value of endocervical curettage after conization for cervical intraepithelial neoplasia. Ann Diagn Pathol. 2012;16(4):245-9. https://doi.org/10.1016/j.anndiagpath.2011.10.005

6. Shaco-Levy R, Meirovitz M, Eger G, Benharroch D, Dreiher J. Post-conization endocervical curettage for estimating the risk of persistent or recurrent highgrade dysplasia. Int J Gynaecol Obstet. 2013;121(1):4952. https://doi.org/10.1016/j.ijgo.2012.10.029

7. Massad LS, Collins YC. Using history and colposcopy to select women for endocervical curettage. Results from 2,287 cases. J Reprod Med. 2003;48(1):1-6. https://doi.org/10.1097/00006254-200305000-00013

8. Solomon D, Stoler M, Jeronimo J, Khan M, Castle P, Schiffman M. Diagnostic utility of endocervical curettage in women undergoing colposcopy for equivocal or low-grade cytologic abnormalities. Obstet Gynecol. 2007;110(2 Pt 1):288-95.

https://doi.org/10.1097/01.AOG.0000270154.69879.09

9. Gage JC, Duggan MA, Nation JG, Gao S, Castle PE. Detection of cervical cancer and its precursors by endocervical curettage in 13,115 colposcopically guided biopsy examinations. Am J Obstet Gynecol. 2010;203(5):481 e1-9. https://doi.org/10.1016/j.ajog.2010.06.048

10. Massad LS, Einstein MH, Huh WK, Katki HA, Kinney WK, Schiffman M, et al. 2012 updated consensus guidelines for the management of abnormal cervical cancer screening tests and cancer precursors. J Low Genit Tract Dis. 2013;17(5 Suppl 1):S1-S27. https://doi.org/10.1097/LGT.0b013e318287d329

11. Massad LS. Selecting Patients for Endocervical Curettage. J Low Genit Tract Dis. 2015;19(4):271-2. 
https://doi.org/10.1097/LGT.0000000000000130

12. Miranda AD, Rodriguez R, Novoa DM, Rojas A, Pachon A, DiazGranados CA. The use of endocervical curettage in women with low-grade squamous intraepithelial lesions or atypical squamous cells of unknown significance on Pap smear. J Low Genit Tract Dis. 2006;10(3):146-50.

https://doi.org/10.1097/00128360-200607000-00005

13. Rose JD, Byun SY, Sims SM, Davis JD. The utility of endocervical curettage: does routine ECC at the time of colposcopy for low-grade cytologic abnormalities improve diagnosis of high-grade disease? Am J Obstet Gynecol. 2012;206(6):530 e1-3.

https://doi.org/10.1016/j.ajog.2012.03.026

14. Pretorius RG, Belinson JL, Azizi F, Peterson PC, Belinson S. Utility of random cervical biopsy and endocervical curettage in a low-risk population. J Low Genit Tract Dis. 2012;16(4):333-8. https://doi.org/10.1097/LGT.0b013e3182480c18

15. Goksedef BP, Akbayir O, Numanoglu C, Corbacioglu A, Guraslan $\mathrm{H}$, Bakir LV, et al. Evaluation of endocervical canal in women with minimal cervical cytological abnormalities. J Low Genit Tract Dis. 2013;17(3): 261-6. https://doi.org/10.1097/LGT.0b013e31826b68c7

16. Poomtavorn Y, Suwannarurk K, Thaweekul Y, Maireang $K$. Diagnostic value of endocervical curettage for detecting dysplastic lesions in women with atypical squamous cells of undetermined significance (ASC-US) and low grade squamous intraepithelial lesion (LSIL) Papanicolaou smears. Asian Pac J Cancer Prev.
2014;15(8):3461-4.

https://doi.org/10.7314/APJCP.2014.15.8.3461

17. Drescher CW, Peters WA, 3rd, Roberts JA. Contribution of endocervical curettage in evaluating abnormal cervical cytology. Obstet Gynecol. 1983;62(3):343-7.

https://doi.org/10.1097/00006250-198309000-00016

18. Saltzman DH, Evans MI, Warsof SL, Friedman AJ. Endocervical curettage as a routine part of colposcopic examinations for abnormal cervical cytology. J Reprod Med. 1985;30(11):871-3.

19. Urcuyo R, Rome RM, Nelson JH, Jr. Some observations on the value of endocervical curettage performed as an integral part of colposcopic examination of patients with abnormal cervical cytology. Am J Obstet Gynecol. 1977;128(7):787-92. https://doi.org/10.1016/0002-9378(77)90722-0

20. Oyer R, Hanjani P. Endocervical curettage: does it contribute to the management of patients with abnormal cervical cytology? Gynecol Oncol. 1986;25(2):204-11. https://doi.org/10.1016/0090-8258(86)90100-9

21. Massad LS, Einstein MH, Huh WK, Katki HA, Kinney WK, Schiffman M, et al. 2012 updated consensus guidelines for the management of abnormal cervical cancer screening tests and cancer precursors. Obstet Gynecol. 2013;121(4):829-46. https://doi.org/10.1097/AOG.0b013e3182883a34

22. Williams DL, Dietrich C, McBroom J. Endocervical curettage when colposcopic examination is satisfactory and normal. Obstet Gynecol. 2000;95(6 Pt 1):801-3.

https://doi.org/10.1097/00006250-200006000-00004 